\title{
Perineal rectosigmoidectomy for strangled rectal prolapse: A case report
}

\author{
Alpha Oumar Toure ${ }^{1^{\star}}$, Cheikh Tidiane Diop ${ }^{1}$, Fode Baba Toure ${ }^{1}$, Thomas Marcel M. Wade ${ }^{1}$, \\ Gabriel Ngom ${ }^{2}$ \\ ${ }^{1}$ Department of General Surgery, Regional Hospital of Ourossogui, Ourossogui, Senegal; \\ *Corresponding Author: alpha.oumar@yahoo.fr \\ ${ }^{2}$ Department of Pediatric Surgery, Aristide Le Dantec Hospital, Dakar, Senegal
}

Received 29 September 2013; revised 25 October 2013; accepted 20 November 2013

Copyright (C) 2014 Alpha Oumar Toure et al. This is an open access article distributed under the Creative Commons Attribution License, which permits unrestricted use, distribution, and reproduction in any medium, provided the original work is properly cited. In accordance of the Creative Commons Attribution License all Copyrights (C) 2014 are reserved for SCIRP and the owner of the intellectual property Alpha Oumar Toure et al. All Copyright (C) 2014 are guarded by law and by SCIRP as a guardian.

\section{ABSTRACT}

Strangled rectal prolapse, the rare disease, is a proctological emergency. Its management is controversial. When it is not reducible and signs of ischemia are present, the Altemeierperineal rectosigmoidectomy remains the best treatment. This study aimed to report our experience on the management of strangled rectal prolapse about 1 case in a 45-year-old man, a holder of a rectal prolapse for 2 years. On admission, he had strangled prolapse for 24 hours with edema. After a vain attempt of manual reduction and installation of necrosis after 48 hours, he had an Altemeier rectosigmoïdectomy. The postoperative course was uneventful and the patient was discharged on the 6 th postoperative day. The results were very good, after one year follow-up.

\section{KEYWORDS}

\section{Strangled Rectal Prolapsed; Altemeier; Rectosigmoïdectomy}

\section{INTRODUCTION}

Rectal prolapse is an intussusception of the rectal wall leading to its expression more or less complete [1]. It is perceived as degrading disability, often unacknowledged. The type of ulcer complications, strangulation or evisceration is rare but is proctological emergencies whose treatment is usually surgical. However, there is no consensus yet on the therapeutic method to use.

The purpose of this study was to report our experience on the management of the strangled rectal prolapse treated by the Altemeier technique in a patient.

\section{CASE REPORT}

Mr. A. BA, 45 years old, was the bearer of anal swelling, painless and reducible, evolving over the past two years with the proctalgia, episodes of rectal bleeding and constipation.

He was admitted to our department for painful and irreducible rectal prolapsed evolving for 24 hours. On examination, the mucous membranes were pale, blood pressure, temperature and pulse were normal. At the anus, there was a prolapse strangled, edematous, dark red measuring $13 \mathrm{~cm}$ long by $8 \mathrm{~cm}$ wide (Figure 1).

The complete blood count showed anemia at $7 \mathrm{~g} / \mathrm{dl}$ and a hematocrit of $29 \%$. Blood glucose was normal.

Given the failure of the manual reduction and installation of necrosis during the transfusion (Figure 2), we decided to perform a recto-sigmoïdectomy followed by anal banding.

The surgery was done under cover of antibiotic prophylaxis based on cefotaxime and metronidazole, but also a transfusion of 2 bags of blood group iso-and iso-Rh.

The intervention was initiated through an anterior incision on the prolapse and continuing through the entire thickness of the wall ofrectum (Figure 3).

Resection of $45 \mathrm{~cm}$ of the rectum and sigmoid was performed followed by a colo-anal anastomosis with absorbable suture braided. The operation ended by anal strapping with an absorbable suture. Antibiotics and sitz baths were prescribed after surgery.

The postoperative recovery was uneventful with bowel function recovery on $2^{\text {nd }}$ post-operative day and he returned home on day 6 postoperatively.

After one year follow-up, the patient showed no recurrence or incontinence or anal stenosis (Figure 4).

\section{DISCUSSION}

Rectal prolapse is an intussusception of the rectum- 


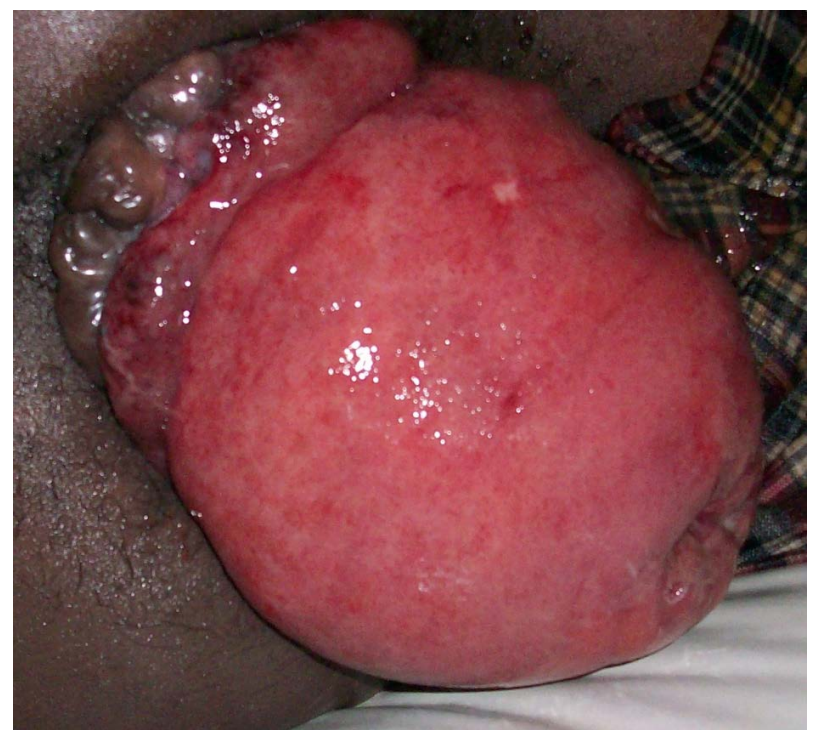

Figure 1. Rectal prolapse strangled and oedematous (Photo Dr. CTDiop).

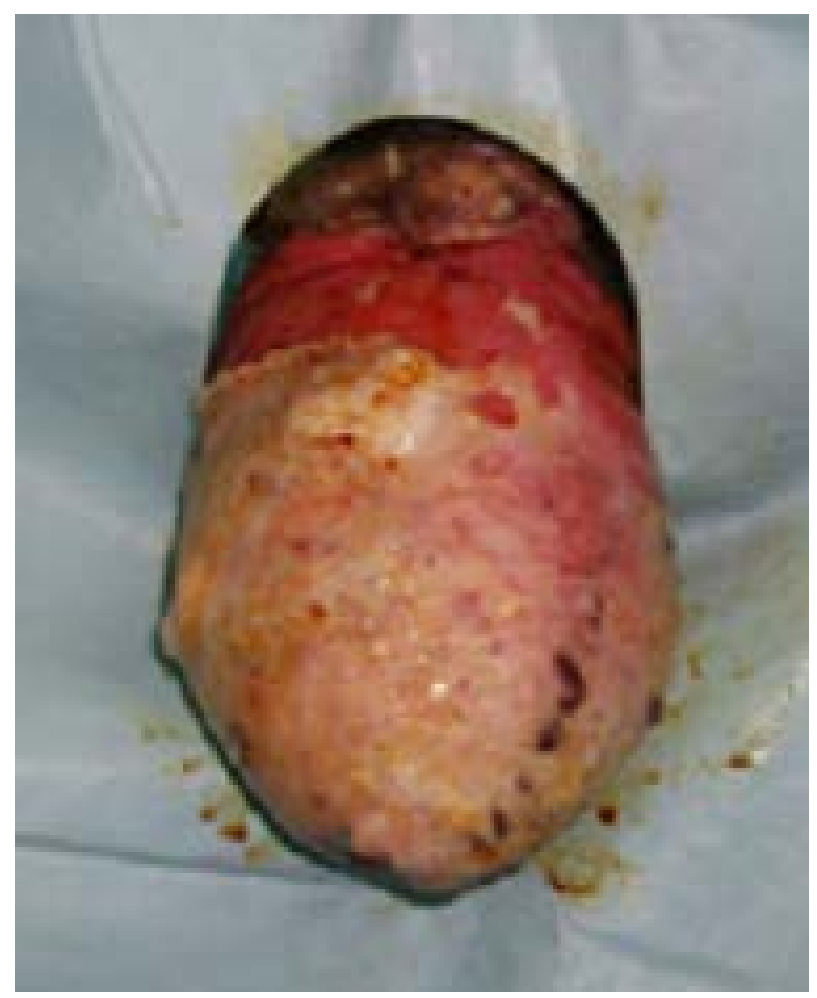

Figure 2. Necrotic rectal prolapse (Photo Dr. CTDiop).

that interests all or part of its various tunics, in a thrust and resulting in its expression more or less complete through the anus [1-3]. Its incidence seems low but it would be rather underestimated because patients rarely consult and "suffer in silence" [1]. There are two etiopathogenicforms: the older woman one, the most common, due to an abdominal hypertension related to childbirth or terminal constipation, forming part of a global disorder

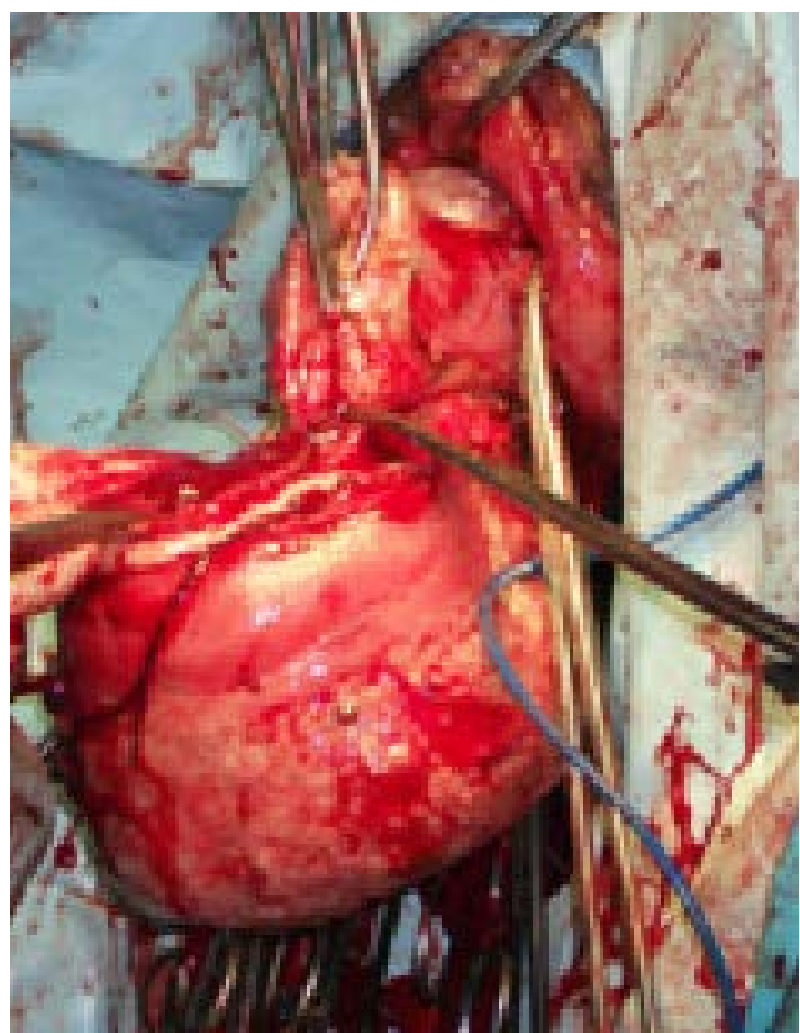

Figure 3. Procto-sigmoidectomy (Photo Dr. CTDiop).

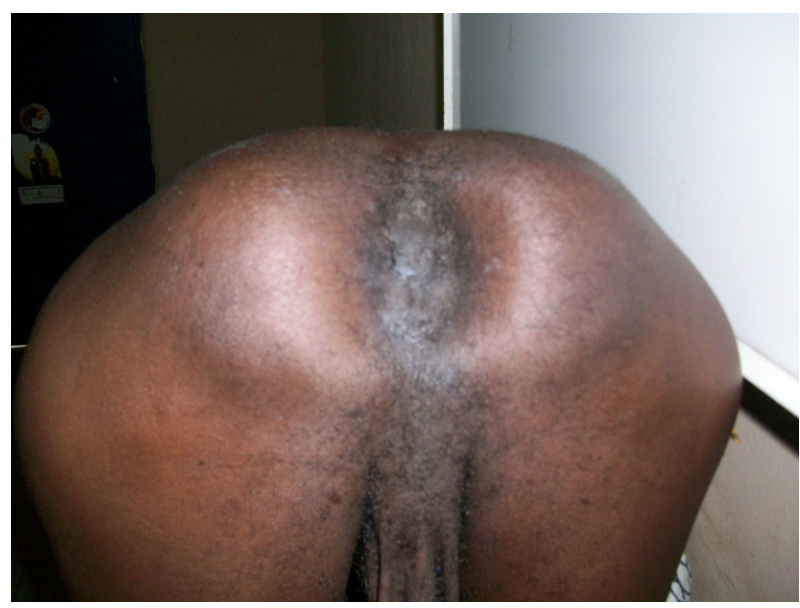

Figure 4. Anus at 1 year postoperatively (Photo Dr. CTDiop).

of pelvi-perinealstatics; and isolated rectal prolapse with a solid perineum described in young adults and is mainly due to a lack of fixation of the rectum $[1,3,4]$.

Complications such as strangulation are rare and require emergency reduction [1]. The strangled rectal prolapse has two clinical forms:

- Sthenic form, the rarest, came after a violent effort, for example an accidental fall. Intense back and abdominal pain, ceaseless tenesmus, dysuria quickly alarme the patient;

- Asthenic form, the most common, occurs readily in 
the elderly, long obsessed with defecation problems. The prolapse is old and has sometimes necessitated reduction maneuvers. The diagnosis may then be delayed: the onset is insidious, more dull pain with heaviness and mental disorders frequently complicate the interpretation of symptoms [1].

In one case as in the other, the essential sign is irreducibility painful of prolapsed rectum. It is edematous, swollen mucosa is purplish red. Rapidly this initial stage is passed, the mucosa becomes cyanotic and sweating is abundant and fetid [1].

There is yet no formal consensus on the technique to use and very few references were found on the management of rectal strangled prolapse [5,6].

Several external maneuvers have been described for the reduction of strangled prolapse: ordinary table sugar for its drying effect on tissue edema, the wet bathing and elastic compression wrap [5-8]. These actions are effective if done before the swelling becomes too great. They must be performed under general anesthesia, gently to avoid the prolapse breaking, source of evisceration $[2,8]$.

Several surgical techniques have been described with the goal of the anatomical anomaly correction and to restore normal anorectal physiology. We distinguish techniques of resection, fixation or a combination of both. The approach may be perineal or abdominal, by laparotomy or laparoscopy [1,2,9]. Abdominal rectopexy techniques such as those Ripstein (anterior rectal sling), Wells (posterior rectal) or Loygue Orr (latero-rectal) are most used. Randriamananjara et al. call first for a colostomy to allow resorption of edema, before proceeding to a rectopexyOrr Loygue [5]. By perineal approach, the interventions of Delorme (mucosectomy and rectal muscle plication) and that of Altemeier (rectosigmoïdectomy with or without colostomy) are most frequent.

When the prolapse is not reducible and signs of ischemia are present, surgery is needed. In this case, the technique of choice remains the perinealproctosigmoidectomy by Altemeier and the results are satisfactory [2,10-12]. Ramanujam operated 8 patients for strangled rectal prolapse by the Altemeier technique and obtained 6 good results and 2 cases of anastomotic leakage requiring a colostomy with good evolution. In the long term, no recurrence was observed [12].

In our case, the attempt of conservative treatment by manual reduction has led to the onset of necrosis, thus justifying the implementation of the Altemeier technique whose results were good after 1 year of follow-up.

\section{CONCLUSIONS}

Although rare, strangled rectal prolapse is a proctological emergency. Its management should suffer no delay to minimize the risk of the onset of necrosis.
Its treatment, although non-consensual, must begin with an external reduction attempt. If this fails, the surgical treatment by the Altemeier technique remains the most appropriate.

\section{REFERENCES}

[1] Contou, J.F. and Godeberge, P. (2007) Prolapsus rectal. Traité de proctologie. Vol. 1, Flammarion, Paris, 147-152.

[2] Soravia, C. and Vollenweider, E. (2004) Prolapsus rectal incarcéré après préparation colique au polyethylene glycol. Gastroentérologie Clinique et Biologique, 28, 11771178. http://dx.doi.org/10.1016/S0399-8320(04)95202-5

[3] De Parades, V., Bauer, P., Villet, R. and Atienza, P. (200) Valeur et limites de la clinique dans les troubles fonctionnels anorectaux (hors algies chroniques). Gastroentérologie Clinique et Biologique, 27, 87-98.

[4] Lechaux, J.P. (2002) Traitement chirurgical du prolapsus rectal complet de l'adulte. Encyclopédie médicale Medix, Techniques Chirurgicales-Appareil Digestif, 40-710, 12 Pages.

[5] Randriamananjara, N. and Rabarioelina, L. (1997) Le prolapsus colo rectal aigu: A propos d'un cas traité. Medecine Afrique Noire, 44, 610-611.

[6] Sarpel, U., Jacob, B.P. and Steinhagen, R.M. (2005) Reduction of a large incarcerated rectal prolapse by use of elastic compression wrap. Diseases of the Colon \& Rectum, 48, 1320-1322. http://dx.doi.org/10.1007/s10350-004-0913-4

[7] Myer, J.O. and Rothenberger, D.A. (1991) Sugar in the reduction of incarcerated prolapsus bowel. Report of the two cases. Diseases of the Colon \& Rectum, 34, 416-418. http://dx.doi.org/10.1007/BF02053694

[8] Coburn, $3^{\text {rd }}$, W.M., Russel, M.A. and Hofstetter, W.L. (1997) Sucrose as an aid to manual reduction of incarcerated rectal prolapse. Annals of Emergency Medicine, 30, 347-349. http://dx.doi.org/10.1016/S0196-0644(97)70174-4

[9] Madiba, T.E., Baig, M.K. and Wexner, S.D. (2005) Surgical management of rectal prolapse. Archives of Surgery, 140, 63-73. http://dx.doi.org/10.1001/archsurg.140.1.63

[10] Yildirim, S., Koksal, H.M. and Baykan, A. (2001) Incarcerated and strangulated rectal prolapse. International Journal of Colorectal Disease, 16, 60-61. http://dx.doi.org/10.1007/s003840000264

[11] Voulimeneas, I., Antonopoulos, C., Alifierakis, E. and Ioannides, P. (2010) Perinealrectosigmoidectomy for gangrenous rectal prolapse. World Journal of Gastroenterology, 16, 2689-2691. http://dx.doi.org/10.3748/wjg.v16.i21.2689

[12] Ramanujam, P.S. and Venkatesh, K.S. (1992) Management of acute incarcerated rectal prolapse. Diseases of the Colon \& Rectum, 35, 1154-1156. http://dx.doi.org/10.1007/BF02251967 